\title{
¿HAY UNA TERCERA ÉTICA A LAS DOS DE WEBER?: \\ Una aclaración conceptual
}

Ulises Schmill Ordóñez

ITAM, México

\begin{abstract}
RESUMEN. Se trata de una contestación a «Nota sobre Los lenguajes de la jurisprudencia, la sociología y la ética. Retribucionismo vs. utilitarismo» de Rodolfo VÁzQUEZ, publicada en este mismo número.
\end{abstract}

Palabras clave: Rodolfo VÁZQUEZ, utilitarismo, retribucionismo.

\section{Is there a third type of Ethics beyond Weber's two kinds? A conceptual clarification}

ABSTRACT. An answer to «Nota sobre Los lenguajes de la jurisprudencia, la sociología y la ética. Retribucionismo vs. utilitarismo» by Rodolfo VÁZQUEZ, included in this volume.

Keywords: Rodolfo VÁZquEZ, utilitarianism, retributivism.

* Fecha de recepción: 11 de octubre de 2016. Fecha de aceptación: 30 de octubre de 2016. 


\section{PRESENTACIÓN DEL TEMA DE ESTAS OBSERVACIONES}

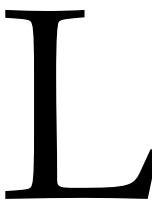

a «Nota sobre Los lenguajes de la jurisprudencia, la sociología y la ética Retribucionismo vs. utilitarismo» escrita por el Dr. Rodolfo VÁZQUEZ, gran amigo y profesor, al libro de mi autoría, contiene una serie de reflexiones muy provocativas sobre la clasificación de las éticas de Max WEBER contenidas en su libro La política como vocación, que yo utilizo en el mío y que ofrece, además, una idea muy interesante sobre la que denomina Ética de la cooperación. Los conceptos expresados por VÁZQUEZ tienen el propósito de aportar un nuevo elemento a las dos clases de éticas que propone WeBER en el libro mencionado. Este es un intento plausible y constituye una aportación que merece ser discutida detalladamente y tomar posición teórica frente a ella.

Dice VÁZQUEZ que una de las ideas directrices de mi trabajo consiste en partir de la distinción weberiana entre la «ética de la convicción» y la «ética de la responsabilidad», distinción que me sirve de «marco teórico para determinar dos modelos explicativos de decisiones y con ellos, dos modelos posibles de interpretación jurídica». En esto le asiste toda la razón. De manera muy ingeniosa, con base en mis reflexiones sobre la obra del gran historiador griego TuCíDIDES, La Guerra del Peloponeso, encuentra una asociación muy importante entre la ética de la convicción y la postura política de Cleón, líder de los atenienses durante parte de la guerra entre Atenas y Esparta, quien obtuvo el acuerdo de la asamblea ateniense de matar a todos los adultos masculinos de la ciudad de Mitilene y vender como esclavos a las mujeres y a los infantes, como retribución por la rebelión que esa ciudad de la isla de Lesbos había llevado a cabo en uno de los momentos más críticos de la historia de la gran ciudad de Atenas, debido a la peste que asoló a su población, peste que tomó como víctima al propio Pericles. Shylock es otro personaje que en la obra de Shakespeare El Mercader de Venecia representa la conducta de un hombre que actúa con base en una ética de la convicción, cuando exige una libra de carne de Antonio, como fue estipulado en el contrato de mutuo que celebraron; en relación con la ética de la responsabilidad la encarna en un personaje que aparece solo una vez en el libro de TUCíDIDES, Diódoto, el otro personaje en el debate sobre Mitilene, que logró la revocación de la sentencia dictada el día anterior por la asamblea, con base en argumentos consecuencialistas, incluso de carácter económico. Todo esto lo relata R. VÁZQUEZ con toda precisión, señalando los textos que he escrito sobre estos apasionantes temas.

En la última parte de su Nota, R. VÁzQuEZ presenta una alternativa a la dualidad de las éticas de la convicción y la responsabilidad, a la que denomina Ética de la cooperación o modelo «Pericles-objetivista». Agradezco profundamente al Dr. VÁzQUEZ las agudas reflexiones sobre estos temas y el tiempo que ha dedicado a formular la tercera alternativa que propone a las éticas de WEBER. Nadie mejor que el propio VÁzQUEZ para exponer esta postura presentada e ideada por él:

Entre el absolutismo moral y el subjetivismo cabe la posibilidad de un objetivismo (mínimo) muy ajeno al dogmatismo y, por el contrario, anclado fuertemente en premisas empírico-racionales, en el marco de una tradición hobbesiana-kantiana. No cualquier alejamiento del subjetivismo nos conduciría irremediablemente a un absolutismo moral. Ambas tradiciones, la hobbesiana y la kantiana, aparecen conectadas en lo que podríamos 
llamar «la práctica social de la discusión moral» que, por una parte, satisface ciertas funciones relacionadas con la superación de conflictos y el facilitamiento de la cooperación a través del consenso y, por otra, comprende ciertos presupuestos procedimentales y aun sustantivos - derechos humanos exigibles como precondiciones del propio discurso moral- apropiados para satisfacer tales funciones.

Este es el párrafo central de sus observaciones, en el que expresa de manera muy concentrada su concepción de la tercera posible posición ética de las dos presentadas por WEBER. Intentaré demostrar en este trabajo que la postura de VÁZQUEZ no es una tercera alternativa a la dualidad sociológica weberiana de las éticas.

\section{EL SENTIDO DEL DUALISMO DE LAS ÉTICAS DE MAX WEBER}

Debemos preguntarnos cuáles son las características y el sentido de las éticas weberianas mencionadas. Por lo pronto podemos decir que son modelos argumentativos, de carácter formal, para llegar a una conclusión sobre la conducta que hay que realizar en una situación determinada. Primeramente debemos exponer en este lugar la forma cómo WEBER hace la presentación de sus dos modelos de éticas.

Es muy importante hacer notar que las éticas de la convicción y de la responsabilidad contienen una máxima fundamental que las determina. Como se trata de explicar sociológicamente la conducta del hombre, WEBER utiliza el concepto kantiano de «máxima» entendido como un principio subjetivo de la conducta. No se trata de normas objetivas, a la manera como aparecen las normas jurídicas en la experiencia social, independientemente de que el contenido de ellas pueda ser interiorizado en la psique de un individuo o de un grupo de individuos. Las máximas son el sentido subjetivo que informa la conducta de un individuo, expresado en una formación lingüística. Dice WEBER con su lenguaje escueto y exacto:

Tenemos que ver con claridad que toda acción éticamente orientada puede ajustarse a dos máximas fundamentalmente distintas entre sí e irremediablemente opuestas: puede orientarse conforme a la «ética de la convicción» o conforme a la «ética de la responsabilidad» (gesinnungsethisch oder verantwortungsethisch). (WEBER PV: 163).

En WEBER encontramos una tipificación de dos modos de proceder en materia ética: el modo de la convicción y el modo de la responsabilidad. Pero esta clasificación es de carácter puramente formal, pues se requiere que se exponga una máxima sustantiva que exprese el criterio de la moralidad, para después proceder a analizar si la conducta de un sujeto se ajusta a esa máxima fundamental sustantiva de la moralidad directamente o si, por el contrario, su conducta ha sido decidida atendiendo a las consecuencias que su aplicación o ejecución puede producir.

\section{EL PRINCIPIO ESTÁTICO DE LOS ÓRDENES NORMATIVOS (LA MORAL)}

En sus investigaciones sobre las características de los órdenes normativos, KELSEN distingue dos clases de órdenes: los que llama «órdenes estáticos de normas» y los que 
denomina «órdenes dinámicos de normas». Son dos tipos de órdenes normativos que no pueden juntarse, a pesar de la opinión contraria del propio KELSEN.

Para una cabal comprensión de lo que se dirá a continuación, es necesario primero exponer el concepto de cuándo un conjunto de normas forman un orden normativo o, si se prefiere, cuándo forman un sistema normativo. Con mucha claridad KELSEN lo expresa de la siguiente manera:

Una pluralidad de normas forma una unidad, un sistema, cuando su validez puede ser atribuida a una norma única como fundamento último de validez. En cuanto fuente común, esta norma fundamental constituye la unidad en la pluralidad de todas las normas que integran el orden. (KELSEN TPD1: 94).

El punto de vista que se asume es el de la determinación de cuándo se consideran dadas las normas de un determinado orden normativo. El principio de acuerdo con el cual se considera existente una norma dentro de un orden normativo, asume dos modalidades, dependiendo del tipo y operancia de la norma fundamental del orden. Según el tipo de norma fundamental (Grundnorm), pueden distinguirse dos clases distintas de órdenes normativos: los estáticos y los dinámicos. No nos ocuparemos de los segundos y concentraremos nuestra atención a los primeros.

La norma fundamental (Grundnorm) de los primeros se considera válida por su contenido, porque este es apreciado como justo, bueno, valioso, conveniente, útil o por cualquier otra característica que convenza a los individuos de su bondad o conveniencia. Y opera de manera muy específica: las normas del orden dependiente de una de estas normas fundamentales se deducen del contenido de la norma fundamental, por procedimientos puramente lógicos. KELSEN lo expone de la siguiente manera:

Las normas de un genero «valen», o sea, la conducta humana indicada por ellas ha de considerarse como debida, en virtud de su sustancia: porque su contenido tiene una cualidad inmediatamente evidente, que le confiere validez. Y las normas reciben esta calificación por el contenido, debido al hecho de ser referibles a una norma fundamental bajo cuyo contenido puede subsumirse el de las normas que integran el orden, como lo particular bajo lo general. (KELSEN TPD1: 95; TPD2: 231).

Conforme al concepto general del orden normativo, cada orden estático de normas tiene una norma fundamental (Grundnorm), del contenido de la cual por pura aplicación de operaciones lógicas se pueden obtener las normas deducidas. Es necesario observar que KELSEN no especifica ninguna norma fundamental en especial, aunque pone diversos ejemplos de ellas, ya que no intenta construir un sistema moral. Es una operación lógica la que determina la pertenencia de una norma específica a un orden normativo de esta especie. La deducción garantiza la validez de las normas deducidas. KELSEN pone los siguientes ejemplos:

Así, por ejemplo, las normas que dicen «no se debe mentir», «no se debe engañar», «se debe mantener la palabra empeñada», «no se debe prestar falso testimonio» pueden ser derivadas de la norma que ordena la veracidad. De la norma «se debe amar al prójimo» pueden derivarse las normas que no se debe ocasionar mal al prójimo y, en especial, no matarlo, ni lesionarlo física o moralmente, y sí auxiliarlo en caso de necesidad. (KELSEN TPD2: 231).

Para concluir la exposición de este importante concepto, es conveniente destacar los siguientes conceptos: 
Puesto que todas las normas de un orden de este tipo están contenidas en el contenido de la norma presupuesta, pueden ser deducidas a partir de ella mediante una operación lógica, mediante una conclusión de lo general a lo particular. (Ibid.).

En consecuencia, es necesario hacer la distinción fundamental entre la descripción, de modo general y abstracto, de la estructura de los órdenes estáticos o morales de normas, y la descripción de un orden moral en particular. Para lograr esto último, tendría que presuponerse un cierto contenido específico como norma fundamental (Grundnorm) y, por deducción lógica, obtener las normas que pueden ser obtenidas de ese contenido presupuesto.

\section{LOS NIVELES DEL LENGUAJE DE LOS ÓRDENES ESTÁTICOS DE NORMAS.}

Es muy conocido en los libros de lógica que en el análisis de los sistemas lógicos tiene que distinguirse entre los diversos niveles de lenguaje.

Hay un lenguaje-objeto que constituye el nivel más bajo de los sistemas lingüísticos y que constituye el objeto de estudio de las disciplinas y de los otros niveles de lenguaje involucrados. Con objeto de ser más explícitos, diremos que el nivel más bajo en los lenguajes de la Moral y de la Ética lo encontramos por las máximas que orientan de hecho la conducta de los individuos, conjunto de máximas al que podemos denominar «Moral empírica» $\left(\mathrm{LM}_{3}\right)$ : el lenguaje de las máximas empíricas que determinan el sentido de los comportamientos morales. Son los criterios que siguen los individuos en su conducta empírica al enfrentarse a los problemas que tratan de resolver en la vida diaria, criterios que pueden formularse verbalmente y que constituyen sus «máximas» o principios subjetivos de su conducta. Estas máximas constituyen el objeto de explicación de cualquier conducta moral observable.

En relación con este lenguaje, existe o debe existir un meta-lenguaje $\mathrm{LM}_{2}$ que permita la descripción ordenada de las máximas constitutivas de la moral empírica de un sujeto. Este meta-lenguaje tiene por tarea la descripción de la norma fundamental (Grundnorm) de contenido específico de la que pueden obtenerse las diversas máximas contenidas en el conjunto que hemos denominado «moral empírica». La determinación y descripción de las máximas de esta moral empírica es una tarea de la psicología o la sociología, es decir, de cualquier disciplina que quiera entender la conducta humana a través del sentido subjetivo que de hecho orienta dichas conductas.

Hay otro nivel de lenguaje que se encuentra sobre estos dos acabados de mencionar, como el meta-meta-lenguaje. Quisiera presentar un pequeño esquema de estos niveles de lenguaje.

$\mathrm{LM}_{1}$ Meta-Ética.

$\mathrm{LM}_{2}$ Ética dogmática.

$\mathrm{LM}_{3}$ Máximas de una moral empírica.

La Meta-Ética, es decir, $\mathrm{LM}_{1}$ es la disciplina más general que determina las características estructurales de toda Ética dogmática $\mathrm{LM}_{2}$. Ella nos dice que toda ética 
dogmática $\mathrm{LM}_{2}$ tiene una norma fundamental con cierto contenido, del cual pueden derivarse otras normas. $\mathrm{LM}_{2}$ es una disciplina dogmática y empírica, en la medida en que puede comprobar el sentido subjetivo que de hecho orienta la conducta de un sujeto o de una pluralidad de ellos.

Las éticas dogmáticas $\mathrm{LM}_{2}$ son varias y son cambiantes, lo que podemos designar diciendo que son sistemas éticos relativos, dependiendo del sujeto, su ambiente y la cultura en la que vive y se desarrolla. Incluso, tratándose de un solo individuo puede comprobarse que su sistema ético personalísimo ha variado en las diversas etapas de su desarrollo y en los diversos entornos en los que desarrolla su actividad.

\section{5. ¿QUÉ ES LA CLASIFICACIÓN DE LAS ÉTICAS DE MAX WEBER?}

Volvamos a analizar la caracterización weberiana de las éticas: la de la convicción y la de la responsabilidad. Para la cabal comprensión de lo que se dirá a continuación, debe tenerse presente el punto de vista sociológico, expuesto por WEBER en su definición de la Sociología:

Debe entenderse por Sociología (en el sentido aquí aceptado de esta palabra con tan diversos significados): una ciencia que pretende entender, interpretándola, la acción social para de esa manera explicarla causalmente en su desarrollo y efectos. (WEBER ES: 129).

Debemos destacar los siguientes conceptos. La sociología está orientada y enfocada a estudiar: 1) la acción social, i.e., la acción «en donde el sentido mentado por su sujeto o sujetos está referido a la conducta de otros, orientándose por esta en su desarrollo»; 2) para entenderla, por medio de la interpretación de su sentido, y 3) de esta manera poderla explicar causalmente, es decir, establecer las causas de la acción social y el desarrollo y efectos que su realización producirá. En WEBER, la Sociología es una ciencia causal de la acción social y esta es su perspectiva teórica fundamental.

Con base en este concepto fundamental de la Sociología hagamos varias precisiones. Primera observación: ninguna de las éticas weberianas formula el contenido de alguna norma fundamental (Grundnorm); es decir, ninguna de las éticas weberianas se encuentra en $\mathrm{LM}_{2}$. En relación con esta observación debemos considerar que la tipificación de sus éticas de la convicción y de la responsabilidad constituyen una clasificación sociológica diferente de las disciplinas constitutivas de $\mathrm{LM}_{2}$. Esto significa que la clasificación sociológica de las éticas weberianas deben ser consideradas como independientes de las éticas dogmáticas contenidas en la clasificación propia de $\mathrm{LM}_{2}$, es decir, dentro de la disciplina que he denominado Ética dogmática. Dada una ética en $\mathrm{LM}_{2}$, la clasificación weberiana de las éticas de la convicción y de la responsabilidad se refieren al comportamiento sociológico posible de los sujetos que han aceptado las normas en $\mathrm{LM}_{3}$, expuestas y sistematizadas en $\mathrm{LM}_{2}$. Esto quiere decir, que los enunciados sociológicos de la clasificación weberiana de las éticas tienen como materia u objeto los contenidos de las éticas $\mathrm{LM}_{3}$ y $\mathrm{LM}_{2}$. Podríamos representar los enunciados de la clasificación weberiana como $\mathrm{LS}_{2}$, i.e., como formando una disciplina sociológica que estudia las causas de las conductas determinadas por una ética específica en $\mathrm{LM}_{2}$ y los posibles desarrollos y efectos de esas conductas, de acuerdo con el concepto del objeto de la Sociología. 
Segunda observación: en relación con cualquier ética dogmática $\mathrm{LM}_{2}$, las éticas weberianas $\mathrm{LS}_{2}$ describen las consecuencias que se obtendrían en el caso de actuar con base en una ética de la convicción o con base en una ética de la responsabilidad.

Tercera observación: podemos tipificar el contenido de cada una de las éticas weberianas diciendo que son métodos posibles de la obtención de las máximas típicas de esas éticas.

Cuarta observación: podemos formular las reglas para la obtención de las consecuencias y efectos de la norma fundamental (Grundnorm) y de las normas deducidas de la siguiente manera:

$\mathbf{L S}_{2 \text { (convición) }}$ : dada una norma fundamental de cualquier sistema ético dogmático $\mathrm{LM}_{2}$, orienta tu conducta de conformidad con las máximas que desprendas puramente del contenido de la norma fundamental (Grundnorm) del sistema ético en cuestión.

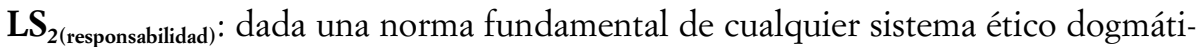
co $\mathrm{LM}_{2}$, orienta tu conducta conforme a las máximas obtenidas mediante el análisis de todas consecuencias posibles que sean previsibles.

WEBER las ejemplifica de la siguiente manera:

Pero sí hay una diferencia abismal entre obrar según la máxima de una ética de la convicción, tal como la que ordena (religiosamente hablando) «el cristiano obra bien y deja el resultado en manos de Dios», como la que ordena tener en cuenta las consecuencias previsibles de la propia acción. (WEBER PV: 164).

Este párrafo de WEBER es central para la comprender la diferencia entre las dos éticas de WEBER. De lo anterior se desprende que cada una de los éticas de WEBER tienen un carácter sociológico, general y formal. Presentan la estructura formal sociológica de cualquier posible ética, sostenida por personas individuales o por grupos sociales, más o menos numerosos.

\section{EFECTOS DE ACTUAR CONFORME A LAS MÁXIMAS DE LAS ÉTICAS DE WEBER}

No solo WEBER ha tipificado los procedimientos deductivos de sus dos éticas, sino que ha analizado los efectos posibles de actuar conforme a cada una de ellas.

En su gran obra Economía y sociedad clasifica las conductas sociales en cuatro libros, que son los siguientes, de los cuales solo analizaremos con más detalle el segundo:

1. La acción social puede ser racional con arreglo a fines, «determinada por expectativas en el comportamiento tanto de objetos del mundo exterior como de otros hombres, y utilizando esas expectativas como "condiciones" o "medios" para el logro de los fines propios racionalmente sopesados y perseguidos». (WEBER ES: 151).

2. Racional con arreglo a valores: «determinada por la creencia consciente en el valor -ético, estético, religioso o de cualquier otra forma como se le interprete- propio y absoluto de una determinada conducta, sin relación alguna con el resultado, o sea puramente en méritos de ese valor». (WEBER ES: 151-2). 
3. Afectiva, «especialmente emotiva, determinada por afectos y estados sentimentales actuales». (WEBER ES: 152).

4. Tradicional «determinada por una costumbre arraigada». (Ibid.).

Nos interesa especialmente la segunda en esta clasificación, pues constituye el origen sociológico de la clasificación de las éticas contenida en su conferencia La Política como vocación. Más adelante especifica la conducta racional con arreglo a valores. Dice:

Actúa estrictamente de un modo racional con arreglo a valores quien, sin consideración a las consecuencias previsibles, obra en servicio de sus convicciones sobre lo que el deber, la dignidad, la belleza, la sapiencia religiosa, la piedad o la trascendencia de una «causa», cualquiera que sea su género, parecen ordenarle. Una acción racional con arreglo a valores es siempre (en el sentido de nuestra terminología) una acción según «mandatos o de acuerdo con "exigencias" que el autor cree dirigidos a él (y frente a los cuales el autor se cree obligado)». (WEBER ES: 153).

Cuáles son los efectos (posibles y plausibles) sociales y personales de actuar conforme a una de las éticas tipificadas.

Cuando las consecuencias de una acción realizada conforme a una ética de la convicción son malas, quien la ejecutó no se siente responsable de ellas, sino que responsabiliza al mundo, a la estupidez de los hombres o a la voluntad de Dios que los hizo así. Quien actúa conforme a una ética de la responsabilidad, por el contrario, toma en cuenta todos los defectos del hombre medio. (WEBER PV: 164).

\section{7. ¿QUÉ ES LA ÉTICA DE LA COOPERACIÓN O MODELO «PERICLES-OBJETIVISTA», O TAMBIÉN, «LA VIGILIA DE PROSPERO» DE R. VÁZQUEZ?}

WEBER dice que las dos máximas que orientan las conductas éticas, la de la convicción y la de la responsabilidad, son «fundamentalmente distintas entre sí e irremediablemente opuestas». (WEBER PV: 163). Esto es así porque WEBER, conforme a su metodología conceptual, construye tipos ideales o tipos puros, como en alguna ocasión expresó. En la magnífica edición que del libro de WeBER Economía y sociedad hizo el profesor Francisco GIL VILLEGAS M. puede leerse en la Introducción del propio profesor, el siguiente párrafo muy ilustrativo:

En cierta forma y como contribución a la sociología, Economía y sociedad es esencialmente un compendio multilateral de tipos ideales, generados por medio de la comparación histórica. Pero los tipos ideales de WEBER no son intentos por destilar alguna esencia universal detrás de las apariencias, sino que son «abstracciones» construidas sobre la reiterada observación de elementos particulares encontrados en la realidad social. Es un proceso cuyo objetivo central es identificar diferencias culturales e históricas [...]. El tipo ideal weberiano puede verse así como un recurso metodológico que plantea un compromiso entre las exigencias de la exactitud histórica y la precisión teórica [...]. No debe olvidarse, por otro lado, que WEBER parte de una epistemología neokantiana [...]. Los tipos ideales enfocan su atención en un aspecto de la realidad social y así ayudan a iluminar un conjunto de conexiones causales; esa es su fuerza metodológica. (WEBER ES: 81-82).

¿Qué es un tipo ideal, cómo se forma o construye y cuál es su función? Estas son preguntas que deben ser contestadas de manera explícita y con la máxima claridad posible. 
La sociología construye conceptos-tipos... y se afana por encontrar reglas generales del acaecer. Esto en contraposición a la historia, que se esfuerza por alcanzar el análisis e imputación causales de las personalidades, estructuras y acciones individuales consideradas culturalmente importantes. La construcción conceptual de la sociología encuentra su material paradigmático muy esencialmente, aunque no de modo exclusivo, en las realidades de la acción consideradas también importantes desde el punto de vista de la historia. (WEBER ES: 145-6).

Quizá valga la pena comparar, para la cabal comprensión de la construcción y función de los tipos ideales, con la primera ley del movimiento de Newton. La descripción que hace del movimiento es lo más alejado de cualquier percepción de él. Más bien postula un movimiento ideal o puro, no observable en instancia alguna. El reposo o el movimiento rectilíneo y uniforme postulado es la hipótesis más alejada de toda experiencia del movimiento que pueda ser encontrado. No hay cuerpo que se mueva de manera rectilínea y uniforme como lo postula su primera ley. Pero este movimiento rectilíneo y a velocidad constante es la base para poder describir cualquier movimiento real, por medio de la influencia de cualquier fuerza que opere sobre el cuerpo en movimiento.

De manera análoga, los tipos ideales de la sociología de WEBER no describen conductas y desarrollos de las conductas reales observables, pero son la condición para poder describir acontecimientos reales históricos por medio de la introducción de variables racionales o irracionales o emotivas en el curso descrito en el tipo ideal o puro.

En todos los casos, racionales como irracionales, se distancia de la realidad, sirviendo para el conocimiento de esta en la medida en que, mediante la indicación del grado de aproximación de un fenómeno histórico a uno o varios de estos conceptos, quedan tales conceptos ordenados conceptualmente. El mismo fenómeno histórico puede ser ordenado por uno de sus elementos, por ejemplo, como feudal, como patrimonial, como burocrático por alguno más todavía por otro como «carismático». Para que con estas palabras se exprese algo unívoco la sociología debe formar, por su parte, tipos puros (ideales) de esas estructuras, que muestren en sí la unidad más consecuente de una adecuación de sentido lo más plena posible; siendo por eso mismo tan poco frecuente quizá en la realidad —en la forma pura absolutamente ideal del tipo- como una reacción física calculada sobre el supuesto de un espacio absolutamente vacío. (WEBER ES: 146-7).

¿Qué es la ética de la cooperación o modelo «Pericles-objetivista» de R VÁzQUEZ? $¿$ Es acaso un tipo ideal sociológico de las Éticas posibles o simplemente constituye la postulación de una ética determinada, a la cual podría concebírsela con cualquiera de los dos tipos weberianos de la ética de la convicción o de la ética de la responsabilidad?

Con la finalidad de contestar estos interrogantes sería conveniente reproducir brevemente algunas líneas de sus Notas a mi libro, donde toma como modelo el discurso fúnebre de Pericles, que le parece contiene un tercer modelo de Ética:

Dicho lo anterior y con el ánimo de ajustarme al relato de TuCíDIDES, pienso que, quizás, el discurso fúnebre de Pericles, reconstruido por el propio historiador de La Guerra del Peloponeso, sería un buen ejemplo de este tercer modelo que propongo. Mientras en Diódoto se vislumbra la justificación de una racionalidad sofista de tipo instrumental, en el caso de Pericles, son la justicia y la igualdad ante la ley (isonomia) las que permean todo su discurso.

VÁZQUEZ parece identificar la postura política del cruel Cleón, con un absolutismo moral, puesto que defendió dogmáticamente la decisión tomada el día anterior por la Asamblea del pueblo ateniense, argumentando, en relación con la rebelión de Mitilene, 
que había tenido lugar en momentos especialmente difíciles para el pueblo ateniense, pues todavía la peste asolaba el territorio de Ática, de modo que hasta el propio Pericles pereció infectado, con lo que los mitilenios incurrieron en la más grave culpa, pues no tenía motivo específico de agravio contra Atenas, pues ni siquiera eran miembros de su Confederación de Delos en donde predominaba la política imperialista de Atenas. Aunque no lo dice expresamente puedo inferir que consideraría la postura de Cleón alineada o sustentada en una ética de la convicción. En cambio, dice que en la postura de Diódoto, que se olvida y rechaza las consideraciones de las culpas, como violación de las más elementales normas, «se vislumbra una justificación de una racionalidad sofista de tipo instrumental», afirmación que permite decir que el discurso de Diódoto es de carácter utilitarista y, por tanto, que considera las consecuencias de la imposición de la pena capital a toda la población de Mitilene. Este discurso se orienta claramente a una ética de la responsabilidad.

Ambas tradiciones, la hobbesiana y la kantiana, aparecen conectadas en lo que podríamos llamar «la práctica social de la discusión moral» que, por una parte, satisface ciertas funciones relacionadas con la superación de conflictos y el facilitamiento de la cooperación a través del consenso y, por otra, comprende ciertos presupuestos procedimentales y aun sustantivos - derechos humanos exigibles como precondiciones del propio discurso moral- apropiados para satisfacer tales funciones.

Por lo pronto debemos observar que dentro del régimen político democrático ateniense era posible sostener públicamente ante la asamblea posturas éticas diversas, como las de Cleón y Diódoto. Pero ello era debido, no a una nueva variante sociológica de las éticas, sino a los postulados de la democracia ateniense.

Debemos observar que los postulados relativistas de la democracia ateniense daban la posibilidad de sostener posturas éticas antagónicas, pero creo que no contienen una tercera postura equidistante a una ética de la convicción y a una ética de la responsabilidad. Cualquier postura política podría exponerse conforme a las máximas sociológicas de una ética de la convicción y la máxima de una ética de la responsabilidad.

El diálogo y la discusión publicas no constituyen una tercera postura ética sociológica, sino postulados políticos, a los que pueden aplicarse las máximas de las dos éticas weberianas.

Ciertamente, la postura ética de Pericles podría sufrir las consecuencias sociológicas que se derivarían de las éticas de la convicción y de la responsabilidad aplicadas a los postulados democráticos. Quizá habría fundamento sociológico e histórico, aunque es un tema controvertido, para considerar que Pericles ocasionó o dio lugar a la guerra del Peloponeso con los decretos que expidió contra Mégara, excluyendo a todos los ciudadanos de esta Polis de utilizar la totalidad de los puertos dentro de su imperio constituido por la Liga o Confederación de Delos. Podríamos pensar que Pericles utilizaba las máximas de una ética de la convicción aplicada estrictamente a sus postulados políticos.

Pero debemos hacer una última reflexión. Es una prueba que intenta demostrar la imposibilidad de la existencia de una tercera alternativa a las éticas weberianas. Pensemos en lo siguiente: en el párrafo transcrito más arriba donde WEBER presenta las máximas de sus dos éticas, dice que «toda acción éticamente orientada puede ajustarse a dos máximas fundamentalmente distintas entre sí e irremediablemente opuestas». 
(WEBER PV: 163, énfasis añadido). Si son distintas e irremediablemente opuestas no pueden aplicarse reflexivamente una a la otra. Alguien puede actuar con base en la máxima de la ética de la convicción y, sin embargo, puede matizar las conclusiones con algunas consideraciones de la ética de la responsabilidad.

La ética postulada por VÁZQUEZ contiene una máxima de conducción o actuación en materia política. Esto es muy importante y debemos reflexionar con WEBER lo que esto implica.

El medio decisivo de la política es la violencia. (WeBER PV: 165). Por política entenderemos solamente la dirección o la influencia sobre la dirección de una asociación política, es decir, en nuestro tiempo, de un Estado. (WeBER PV: 82). Política significará, para nosotros, la aspiración (Streben) a participar en el poder o a influir en la distribución del poder entre los distintos Estados o, dentro de un mismo Estado, entre los distintos grupos de hombres que lo componen. (WEBER PV: 84). Dicho Estado solo es definible sociológicamente por referencia a un medio específico que él, como toda asociación política, posee: la violencia física [...]. La violencia no es, naturalmente, ni el medio normal ni el único medio de que el Estado se vale, pero sí es $s u$ medio específico. Hoy, precisamente, es especialmente íntima la relación del Estado con la violencia [...]. Hoy, por el contrario, tendremos que decir que Estado es aquella comunidad humana que, dentro de un determinado territorio [...] reclama (con éxito) para sí el monopolio de la violencia física legítima. (WEBER PV: 83).

Reconoce WEBER que el Estado no solo se vale de la violencia física legítima, la cual no es el medio normal ni el único medio del que echa mano. Muchos otros medios tiene el Estado para llevar a cabo las ingentes tareas que ha adoptado. El Estado es una relación de dominación de hombres sobre hombres y para ello y su subsistencia necesita «que los dominados acaten la autoridad que pretenden tener quienes en ese momento dominan». (WEBER PV: 84-5). Esta obediencia y sus motivos son los que WEBER expone como criterios de legitimidad: el tradicional, el carismático y el de la legalidad, criterios que aquí no es el lugar para exponerlos con detalle. El tercero, el de la legalidad, se encuentra basado:

[...] en la creencia en la validez de preceptos legales y en la competencia objetiva fundada sobre normas racionalmente creadas, es decir, en la orientación hacia la obediencia a las obligaciones legalmente establecidas. (WEBER PV: 85).

Este criterio de legitimidad es el que opera en los servidores del Estado y que consigna Pericles en la oración fúnebre pronunciada ante el pueblo ateniense, en el segundo año de iniciada esa cruel guerra, donde legitima el régimen democrático ateniense.

Tenemos un régimen de gobierno que no envidia las leyes de otras ciudades, sino que más somos ejemplo para otros que imitadores de los demás. Su nombre es democracia por no depender el gobierno de pocos, sino de un número mayor; de acuerdo con nuestras leyes, cada cual está en situación de igualdad de derechos en las disensiones privadas, mientras que según el renombre que cada uno, a juicio de la estimación pública, tiene en algún respecto, es honrado en la cosa pública [...]. Y al tiempo que no nos estorbamos en las relaciones privadas, no infringimos la ley en los asuntos públicos, más que nada por un temor respetuoso, ya que obedecemos a los que en cada ocasión desempeñan las magistraturas y a las leyes, y de entre ellas, sobre todo a las que están legisladas en beneficio de los que sufren la injusticia, y a las que por su calidad de leyes no escritas, traen una vergüenza manifiesta al que las incumple. (TuCíDIDES HGP: 257-8).

Explicitando su concepción política democrática, VÁZQUEZ obtiene las siguientes consecuencias: 
Ambas tradiciones, la hobbesiana y la kantiana, aparecen conectadas en lo que podríamos llamar «la práctica social de la discusión moral» que, por una parte, satisface ciertas funciones relacionadas con la superación de conflictos y el facilitamiento de la cooperación a través del consenso y, por otra, comprende ciertos presupuestos procedimentales y aún sustantivos - derechos humanos exigibles como precondiciones del propio discurso moral- apropiados para satisfacer tales funciones.

Este párrafo de VÁZQUEZ contiene el concepto fundamental de la posición propuesta denominada muy imaginativamente como «modelo Pericles-objetivista» o «ética de la cooperación».

\section{CONTRASTE CON EL PESIMISMO DE WEBER}

Sin duda alguna es posible afirmar que la postura política de Pericles, que acepta y propugna VÁZQUEZ, es la ideología que sustenta un régimen político democrático, en especial el ateniense. Históricamente los hechos son mucho más complejos, pues Pericles ha sido idealizado como un modelo de conducta política democrática y, sin embargo, fue el que desencadenó la guerra con los lacedemonios y permitió el ascenso de estrategas de la calaña de Cleón y del inteligente y narcisista Alcibíades, que tantas desgracias produjo a los atenienses, descontando la calumnia a su persona por parte del autor cómico Aristófanes, en su obra Los Acarnienses.

Tratándose del ejercicio del poder, de la dominación, las posturas éticas pueden tener consecuencias intolerables y son, como diría un jurista, improcedentes, en virtud que el ámbito de la política y el poder tienen sus propias reglas, radicalmente distintas de cualquier ética que se postule.

Ninguna ética del mundo puede resolver tampoco cuándo y en qué medida quedan «santificados» por el fin moralmente bueno los medios y las consecuencias laterales moralmente peligrosos. El medio decisivo de la política es la violencia... (WEBER PV: 165).

Por ello, surge el problema de si la política puede ser santificada, es decir, volverse buena, a pesar de la utilización de su medio específico: la violencia, pues no es posible «decretar éticamente qué fines pueden santificar tales o cuáles medios». (WEBER PV: 167). En dos párrafos muy ilustrativos dice:

También los cristianos primitivos sabían muy exactamente que el mundo está regido por los demonios y que quien se mete en política, es decir, quien accede a utilizar como medios el poder y la violencia, ha sellado un pacto con el diablo, de tal modo que ya no es cierto que en su actividad lo bueno siempre produzca el bien y lo malo el mal, sino que frecuentemente sucede lo contrario. Quien no ve esto es un niño, políticamente hablando. Las distintas éticas religiosas se han acomodado de diferente modo al hecho de que vivimos insertos en ordenaciones vitales distintas, gobernadas por leyes distintas entre sí. El politeísmo helénico sacrificaba tanto a Afrodita como a Hera, a Apolo como a Dionisos, y sabía bien que no era raro el conflicto entre estos dioses. (WEBER PV: 168).

Si vivimos dentro de ordenaciones distintas, necesariamente surge el problema de sus relaciones y de las armonías y conflictos entre ellas, como el acuerdo y la discordia de los dioses. Por ello, WEBER dice:

La singularidad de todos los problemas éticos de la política está determinada sola y exclusivamente por su medio específico, la violencia legítima en manos de las asociaciones humanas. (WEBER PV: 171). 
El político puede plantearse cualquier fin que se quiera, dependiendo de su circunstancia, pues no hay fin social que no quepa dentro del molde de la política, que tiene un carácter formal. Para la realización de cualquier fin que se proponga por los gobernantes o los políticos es necesaria la utilización del medio específico de la política y «está condenado a sufrir sus consecuencias específicas». (Ibid.). ¿Cuáles son estas?

Quien quiera imponer sobre la tierra la justicia absoluta valiéndose del poder necesita para ello seguidores, un «aparato» humano. Para que este funcione tiene que ponerle ante los ojos los necesarios premios internos y externos. En las condiciones de la moderna lucha de clases, tiene que ofrecer como premio interno la satisfacción del odio y del deseo de revancha y, sobre todo, la satisfacción del resentimiento y de la pasión pseudoética de tener razón; es decir, tiene que satisfacer la necesidad de difamar al adversario y de acusarle de herejía. Como medios externos tiene que ofrecer la aventura, el triunfo, el botín, el poder y las prebendas. El jefe depende por entero para su triunfo del funcionamiento de este aparato y por esto depende de los motivos del aparato y no de los suyos propios. (WeBER PV: 171-2).

En consecuencia, con ello se han presentado las consecuencias de la utilización de la política en los asuntos humanos y de cómo por la utilización de su medio específico, puede fracasar o por lo menos desviarse de sus finalidades fundamentales. La política es un medio formal, no sustancial, que admite en su interior cualquier finalidad humana y tiene las consecuencias inherentes a cualquier realización de las empresas humanas. El problema es que el medio de la política no es renunciable y son inevitables las consecuencias inherentes a su utilización.

\section{EL DIÁLOGO DE MELOS}

El siguiente es el diálogo entre los generales atenienses y los gobernantes (magistrados) y ciudadanos más importantes de la isla de Melos. Como todo lo relativo a TUCÍDIDES contiene mucha sabiduría y constituyen modelos para entender la vida humana y la política. Este diálogo es un ejemplo de cómo utilizar un método democrático del diálogo para finalidades autocráticas e imperialistas. Este diálogo tiene presupuestos contrarios a los postulados por VÁZQUEZ con su modelo «Periclesobjetivista».

En el apartado 84 del Libro V del libro de TucíDIDEs Historia de la Guerra del Peloponeso se inicia el relato de lo que aconteció a la pequeña isla de Melos cuando se enfrentó con el poderío de la democrática Atenas. Así relata los antecedentes del famoso acontecimiento que ha aterrorizado a muchos intelectuales que lo han comentado.

Además, los atenienses organizaron una expedición contra la isla de Melos con treinta naves propias, seis de Quíos y dos de Lesbos, y con mil doscientos hoplitas, trescientos arqueros de a pie y veinte de a caballo, todos de Atenas, y unos mil quinientos hoplitas de sus aliados los isleños. Los melios son colonia de los lacedemonios y no querían ser vasallos de los atenienses como los demás isleños, sino que primero se mantuvieron en paz como neutrales y después, como los atenienses devastando la isla les forzaron a ello, entraron abiertamente en guerra. Así pues, los estrategos Cleomedes, hijo de Licomedes y Tisias, hijo de Tisímaco, acamparon en la isla con sus fuerzas, y antes de causar daños en ningún sitio, enviaron primero unos embajadores que trataran con los habitantes. Los melios no les introdujeron ante la Asamblea, sino que los invitaron a hablar ante los magistrados y los ciudadanos más importantes sobre la comisión que traían. (Tuc. V: 84. Cf. III: 91). 
Puede uno imaginarse claramente la escena de los atenienses y los melios, los primeros frente a un grupo de magistrados y hombres importantes, apoyados con los soldados armados y dispuestos en orden para llevar a cabo cualquier actividad que se les requiriera. Lo primero que dijeron los atenienses, conocedores del modo de proceder de las asambleas populares, es que proponían llevar a cabo un diálogo entre las pocas personas presentes, contestando las preguntas que se les formularan y manifestando sus opiniones como fueran surgiendo del diálogo. Con ello obtendría ambos bandos ventajas indudables, pues el diálogo se llevaría sin el pueblo, «sin duda para que la muchedumbre no se deje engañar al oírnos en un discurso seguido razonamientos especiosos e irrefutables (pues conocemos que esto es lo que significa el traernos ante un corto número de personas)». (Tuc. V: 84). Por tanto, dialogarían fuera del barullo de las asambleas multitudinarias, las que reaccionan emotivamente, ante los discursos «especiosos e irrefutables». Esto puede significar, que entre un número pequeño de seres humanos puede entablarse un diálogo racional, donde funcionen los cerebros y no las vísceras encendidas por las palabras, como señalaba el retórico y filósofo Gorgias. Los delegados de los melios no desaprobaron la proposición ateniense.

Al contestar los melios plantearon un contraste radical entre el diálogo pacífico de los argumentos y contra-argumentos, y los hechos de la guerra que son «muy desemejantes de esa manera de obrar». (Tuc. V: 86). Afirman que la guerra es ya un hecho y no se encuentran en la etapa previa de las amenazas. Plantean con mucha claridad el resultado del diálogo: «el fin de esta reunión nos traerá, si vencemos con apoyo en la justicia y por ello no cedemos, la guerra, y si nos sometemos, la esclavitud». (Ibid.).

Descalificando las últimas frases de los melios, ridiculizándolas con palabras como «Si habéis venido a hacer suposiciones sobre el futuro o a cualquier otra cosa que a tomar una decisión en bien de la salvación de la ciudad ateniéndonos a las circunstancias actuales y a lo que veis ante vuestros ojos». (TuC V: 87) se percibe la actitud prepotente de los de Atenas, al decir «pondremos fin a nuestras palabras», pues los melios tienen ante sus ojos el ejército descrito anteriormente y en su pensamiento su aniquilación.

El párrafo 89 es central para comprender la situación de los melios y la decisión y política ateniense. Señalan los atenienses que no harán un discurso largo y poco persuasivo, «lleno de hermosas palabras», intentando justificar la legitimidad de lo que piensan realizar, expresando lo siguiente:

1. Que el imperio ateniense es justo porque derribaron el poderío de los Medos, luchando contra ellos.

2. O que lo que piensan hacer con los melios es un castigo por haberles inferido un agravio.

Los melios no convencerán a los atenienses diciendo:

3. Que no se han unido a ellos porque son una colonia de los lacedemonios.

4. O que nunca les han causado daño alguno.

Estos últimos son argumentos posibles que podían haber utilizado los melios para demostrar lo indebido e injustificado del ataque ateniense a su pequeña isla, que suponían protegida por su polis protectora, Esparta. La conclusión obtenida por los atenienses es la siguiente: 
[...] guiándonos de nuestro pensamiento sincero, puesto que sabemos $-\mathrm{y}$ hablamos con quien lo sabe- que la justicia prevalece en la raza humana en circunstancias de igualdad, y que los poderosos hacen lo que les permiten sus fuerzas y los débiles ceden ante ellos. (TuC. V: 89. Énfasis añadido).

Es tesis de TuCíDIDES que la invocación de la justicia, cualquiera cosa que ella sea, opera en un diálogo únicamente en circunstancias de igualdad y los argumentos que la expresan tienen algún resultado siempre y cuando los sujetos o las entidades en conflicto se encuentren en situación de igualdad en cuanto a poder. En igualdad de poder, entonces funcionan los argumentos de justicia; el poderoso frente al menos poderoso, hace lo que puede y quiere y el más débil cede o se somete al poderoso.

Los melios hacen un último intento de convencer con argumentos a los atenienses. Para ello utilizan una tesis consecuencialista y hasta utilitaria, pues los atenienses excluyeron los argumentos de justicia y se atuvieron a argumentos de conveniencia. Aceptando esta regla impuesta por los atenienses los melios aducen que los atenienses no deben destruir a Melos, puesto que «el que esté en un momento dado en peligro, puede ayudarse convenciendo con razones aceptables aunque no lleguen a un rigor lógico». (Tuc. V: 90).

No es a vosotros a quienes menos favorece esto, y tanto más cuanto que como vuestra caída iría acompañada de un castigo terrible, seríais para los demás un ejemplo de escarmiento. (Tuc. V: 90).

Es un intento desesperado de los melios para convencer a los atenienses de desistir del plan de aniquilamiento de la isla: si su imperio fuera destrozado, si aniquilaran su fuerza, el castigo que caería sobre ellos sería implacable, pues lo impondría como escarmiento de lo hecho y prevención para los demás.

Los atenienses, ensoberbecidos por el poder, afirman sobre esta posibilidad que «no nos descorazonaremos por el fin de nuestro imperio, si es que llega a ser destruido». (Tuc. V: 91). A continuación hacen una observación sociológica muy importante: los más crueles en su conducta no son los sujetos que imperan sobre otros, «sino los vasallos del país dominador cuando le atacan y vencen». (Ibid.).

En los siguientes párrafos se expresan las consideraciones de los sujetos imperiales. Se expone una teoría del imperialismo, desde el punto de vista del dominador.

[...] ahora vamos a demostrar que estamos aquí por el bien de nuestro imperio y que nuestras palabras irán dirigidas a la salvación de vuestra ciudad, pues queremos someteros sin trabajo y que vosotros os salvéis con provecho para ambos. (Ibid.).

Y en ese punto del diálogo, los melios ofrecen permanecer neutrales en relación con la guerra entre Atenas y los lacedemonios, ofrecimiento que es radicalmente rechazado por la polis imperial, con un argumento sorprendente, digno de meditarse con detenimiento:

No; porque vuestra enemistad no nos perjudica tanto como vuestra amistad, que es para nuestros vasallos un signo manifiesto de nuestra debilidad, mientras que vuestro odio lo es de nuestro poder. (TuC. V: 95).

Aquí se encuentra expresada la lógica interna del imperialismo y las consecuencias de la disparidad en el poder entre dos entidades políticas. El poderoso ejerce el poder sobre sus vasallos, los que por los perjuicios que sufren se oponen a aquel y se genera 
el odio hacia los dominadores. Este odio es la señal evidente del ejercicio del poder del dominador sobre los dominados, mientras que la amistad no sería otra cosa que el signo de un poder benevolente, que no se ejecuta y es un signo de debilidad para los demás entidades sujetas al poder imperial. Por ello, el odio de los vasallos es la consecuencia ineludible de unas relaciones inmutables: el odio de los vasallos los impulsa a intentar constantemente a desobedecer a los dominadores, los cuales se encuentran en la coyuntura de la necesidad de incrementar sus actos de dominación y, por tanto, de afirmación del poder imperial. Es lo que he llamado La ley del jabalí, debido a que tomé como modelo de ella la conducta de Ricardo III, quien en su escudo de armas tenía representado a un jabalí.

Dadas dos entidades con poderes diferentes, el poderoso abusa de su poder y el dominado, el súbdito, no tiene otro destino que odiar al poderoso, burlarse de él, manifestarse en su contra gritando todas sus inconformidades y resignándose a vivir en las condiciones y con las cargas que generan sus odios. Los atenienses deducen un comportamiento de los súbditos, que a los atenienses les parecen dignos de ser despreciados:

[...] ni queráis tampoco asemejaros al gran número de los que, siéndoles posible salvarse todavía con recursos propios de hombres cuando estando en situación difícil les abandonan las esperanzas fundadas en realidades visibles, se vuelven a las fundadas en cosas inciertas: la mántica, los oráculos y cuantas otras cosas semejantes producen estragos al llevar consigo la esperanza. (Tuc. V: 103).

Claramente se percibe en estas palabras el ateísmo sofístico de nuestro autor, el que nunca en su obra citó a ninguno de los dioses griegos participando en los acontecimientos que narra.

Si ahora hacemos una aplicación de los conceptos de las éticas de WEBER a este terrible diálogo, podemos concluir que los atenienses actuaban con base en una ética de la convicción, consistente en la regla de ejercer el poder sobre sus súbditos, sin importar las consecuencias remotas de ello. Mientras que los melios actuaban fundamentalmente con base en una ética de la responsabilidad, todas vez que la totalidad de sus argumentos estaban orientados a salvar a su polis de la ejecución de las amenazas de los atenienses. El Libro V lo concluye TUCíDIDES con las siguientes escuetas palabras, que contrastan con la enormidad de la conducta de los atenienses:

Pero luego, al venir en vista de esto de Atenas un nuevo ejército al mando de Filócrates, hijo de Demeas, y quedar ya asediados los melios con todo rigor, añadiéndose una traición en su campo, capitularon ante los atenienses, quedando su suerte a discreción de estos. Y los atenienses ejecutaron a todos los melios en edad viril que cayeron en sus manos y redujeron a la esclavitud a los niños y mujeres. Fueron ellos mismos quienes, enviando seguidamente quinientos colonos, poblaron la ciudad. (TUC. V: 116).

Este fue el trágico desenlace de este diálogo, el cual es un ejemplo de que, en ciertas circunstancias, conducen a la afirmación y exacerbación del poderío de un Estado, cuando no está dispuesto a dejar de ejercer el poder, con base en consideraciones ideológicas de justicia y justificaciones históricas. Con ello se confirma la tesis de WEBER de la autonomía de las reglas de operancia en el ejercicio del poder y de su independencia de cualquier ética posible. 


\section{CONCLUSIÓN}

Por tanto, concluyo que, en mi opinión, la «Ética de la cooperación» o modelo «Pericles-objetivista» de VÁZQUEZ no es una tercera alternativa sociológica a las éticas de WEBER, sino que es una ética dogmática $\mathrm{LM}_{2}$, democrática, libertaria y pacífica a la que puede considerársele como ética de la convicción o como ética de la responsabilidad, dependiendo del enfoque sociológico que se utilice.

\section{BIBLIOGRAFÍA}

Kelsen, H., 1946: TPD1, La Teoría Pura del Derecho. Introducción a la Problemática Científica del Derecho, Buenos Aires: Editorial Losada, S. A., trad. Jorge G. Tejerina.

- 2011: TPD2, Teoría Pura del Derecho, Buenos Aires: Ediciones Colihue, trad. Fernanda Aren, Natalia Dassieu y Silvina Rotemberg.

Schmill, U., 2016: LJSE, Los Lenguajes de la Jurisprudencia, la Sociología y la Ética, Valencia: Tirant lo Blanch.

- 2005: CJ, La Conducta del Jabali, Dos ensayos sobre el poder: Kafka y Shakespeare, México: Ediciones Coyoacán.

Weber, M., 1989: PV, «La Política como Vocación» en el Político y el Cientifico, México: Alianza Editorial, trad. Francisco Rubio Llorente.

- 2014: ES, Economía y Sociedad, México: Fondo de Cultura Económica, ed. revisada, comentada y anotada por Francisco Gil Villegas.

TuCíDIDES, 1967: HGP, Historia de la Guerra del Peloponeso, Madrid: Librería y Casa Editorial Hernando, S. A., trad. Francisco Rodríguez Adrados. 